\title{
Loss of Neuronal Integrity during Progressive HIV-1 Infection of Humanized Mice
}

\author{
Prasanta K. Dash, ${ }^{1}$ Santhi Gorantla, ${ }^{1}$ Howard E. Gendelman, ${ }^{1,4}$ Jaclyn Knibbe, ${ }^{1}$ George P. Casale, ${ }^{3}$ Edward Makarov, ${ }^{1}$ \\ Adrian A. Epstein, ${ }^{1}$ Harris A. Gelbard,,${ }^{5,67,8}$ Michael D. Boska, ${ }^{2}$ and Larisa Y. Poluektova ${ }^{1}$ \\ Departments of ${ }^{1}$ Pharmacology and Experimental Neuroscience, ${ }^{2}$ Radiology, ${ }^{3}$ Surgery, and ${ }^{4}$ Internal Medicine, University of Nebraska Medical Center, \\ Omaha, Nebraska 68198, and ${ }^{5}$ Center for Neural Disease and Development, and Departments of ${ }^{6}$ Neurology, ${ }^{7}$ Pediatrics, and ${ }^{8}$ Microbiology, University of \\ Rochester Medical Center, Rochester, New York 14642
}

Neuronal damage induced by ongoing human immunodeficiency virus type 1 (HIV-1) infection was investigated in humanized NOD/ scid-IL-2R $\gamma_{c}^{\text {null }}$ mice transplanted at birth with human CD34-positive hematopoietic stem cells. Mice infected at 5 months of age and followed for up to 15 weeks maintained significant plasma viral loads and showed reduced numbers of CD4 ${ }^{+}$T-cells. Prospective serial proton magnetic resonance spectroscopy tests showed selective reductions in cortical $N$-acetyl aspartate in infected animals. Diffusion tensor imaging revealed structural changes in cortical gray matter. Postmortem immunofluorescence brain tissue examinations for neuronal and glial markers, captured by multispectral imaging microscopy and quantified by morphometric and fluorescence emission, showed regional reduction of neuronal soma and synaptic architectures. This was evidenced by loss of microtubule-associated protein 2 , synaptophysin, and neurofilament antigens. This study is the first, to our knowledge, demonstrating lost neuronal integrity after HIV-1 infection in humanized mice. As such, the model permits studies of the relationships between ongoing viral replication and virusassociated neurodegeneration.

\section{Introduction}

Human immunodeficiency virus 1-associated neurocognitive disorders (HAND) remain the most common CNS disease linked to advanced viral infection and present despite the widespread use of antiretroviral therapy (Antinori et al., 2007). Although considerable research is directed towards understanding disease pathobiology, little is known about disease onset and progression. How advanced viral infection elicits neuronal damage is linked to immune, neural cell, and tissue pathobiological events. These are critical in ultimately producing cognitive, behavioral, and motor disorders and causing disabling morbidity in infected people (McArthur et al., 2010).

Virus invades the CNS within 1-2 weeks after viral infection coincident with the peak of viremia and seen within perivascular macrophages and lymphocytes (Davis et al., 1992; Horn et al., 1998; Williams et al., 2001). During the seroconversion reaction, mild aseptic meningitis is observed in up to $20 \%$ of infections (Atwood et al., 1993; Newton, 1995; Gray et al., 1996; del Saz et al., 2008). The long-term sequelae of such events to the brain are incompletely understood (Boufassa et al., 1995; Wallace et al., 2001). Although such pathobiological events are best studied in animal models of human disease (Kraft-Terry et al., 2009), gaps

Received Oct. 19, 2010; revised Dec. 14, 2010; accepted Dec. 18, 2010.

This work was supported by National Institutes of Health Grants 1P01 DA028555, P20 RR15635, 1 P01 NS04398501, 2R37 NS36126, 5 P01 DA026146, and 5 P01 MH64570-03. We acknowledge Deepa Roy, Sidra Akhter, and Tanuja Gutti for technical assistance.

Correspondence should be addressed to Dr. Howard E. Gendelman, Department of Pharmacology and Experimental Neuroscience, University of Nebraska Medical Center,0maha, NE68198-5215.E-mail:hegendel@unmc.edu. DOI:10.1523/JNEUROSCI.5473-10.2011

Copyright $\odot 2011$ the authors $\quad 0270-6474 / 11 / 313148-10 \$ 15.00 / 0$ in understanding human immunodeficiency virus 1 (HIV-1) neuropathogenesis parallel the limited availability of relevant model systems. As lentiviral infections are host cell specific, the mainstay for studies of human disease have centered on the use of rhesus macaques infected with simian immunodeficiency virus (SIV) (Lackner et al., 1991; Narayan et al., 1995). Although this model has yielded insights into viral pathobiology and can, in part, mimic human disease, existing limitations in terms of cost, conduct, and availability to investigators have hampered research progress. This has galvanized efforts to develop disease-relevant rodent models (Santoro et al., 1994; Toggas et al., 1994; Persidsky et al., 1996; Reid et al., 2001; Kim et al., 2003; Potash et al., 2005). Nonetheless, such models, while demonstrating relevance for studies of human disease diagnosis and therapies, have also met with limitations. These limitations include impaired graft survival and the inability to mimic progressive HIV infection and neuroAIDS, in particular. The recent development of humanized $\mathrm{NOD} /$ scid-IL-2R $\gamma_{\mathrm{c}}^{\text {null }}$ (NSG), BALB/c-Rag2 ${ }^{-1-} \gamma_{\mathrm{c}}{ }^{-1-}$, and $\mathrm{NOD} /$ scid mice by transplanting with human cord blood isolated $\mathrm{CD} 34^{+}$hematopoietic stem cells (HSCs), or with fetal liver and thymus, have overcome many of these limitations. Indeed, humanized mice can facilitate studies of chronic HIV-1 infection in immune grafts that are sustained for the lifetime of the animal (for review, see Van Duyne et al., 2009). Importantly, in the field of neuroAIDS, this model may identify relationships between HIV-1 disease progression and neuropathobiology.

To these ends, NSG mice were transplanted at birth with CD34 ${ }^{+}$HSCs (CD34-NSG), and then infected with HIV-1. During progressive viral infection, we investigated when and to what extent neuronal injuries occur after infection onset and how such 
changes correspond to immune, neuronal, and glial aberrations. The data showed that progressive viral infection correlated with loss of neuronal integrity. As such, this model can uncover relationships between ongoing viral replication and its associated neural dysfunction, and is useful for studies of HIV-1 neuropathogenesis and therapeutic development.

\section{Materials and Methods}

Generation of CD34-NSG mice. Animals were obtained from The Jackson Laboratory and bred under specific pathogen-free conditions in accordance with the ethical guidelines for care of laboratory animals at the University of Nebraska Medical Center and set forth by the National Institutes of Health.

$\mathrm{CD} 34^{+}$cells were obtained from fetal liver. Tissues were provided by the University of Washington, Laboratory of Developmental Biology, supported by National Institutes of Health Award 5R24HD000836 from the Eunice Kennedy Shriver National Institute of Child Health and $\mathrm{Hu}-$ man Development. CD34 ${ }^{+}$cells were enriched using immunomagnetic beads $\left(\mathrm{CD} 34^{+}\right.$selection kit; Miltenyi Biotec). Purity of CD $34^{+}$cells was $>90 \%$ by flow cytometry. Cells were transplanted into newborn mice irradiated at 1 Gy using a C9 cobalt 60 source (Picker Corporation). $\mathrm{CD} 34^{+}$cells were injected intrahepatically at $10^{5}$ cells/mouse in $20 \mu \mathrm{l}$ of PBS using a 30 gauge needle. The levels of engraftment and number of human cells in peripheral blood were analyzed by flow cytometry.

Flow cytometry. Peripheral blood was collected from the submandibular vein in EDTA-coated tubes by using lancets (MEDIpoint) or by cardiocentesis at the study end. Blood leukocytes and spleen cell suspensions (collected at end point of the experiment) were tested for human pan-CD45, CD3, CD4, CD8, CD14, and CD19 markers as six-color combinations. Antibodies and isotype controls were obtained from BD Biosciences Pharmingen, and staining was analyzed with a FACSDiva (BD Biosciences Immunocytometry Systems). Results were expressed as percentages of total number of gated lymphocytes. The percentages of CD4and CD8-positive cells were obtained from the gate set on human $\mathrm{CD} 3^{+}$ cells. Four HIV-1-infected and six control-uninfected animals (all male) were analyzed.

HIV-1 infection and peripheral viral load. At 22 weeks of age, male mice were injected intraperitoneally with HIV-1 $1_{\mathrm{ADA}}$ using a single dose of $10^{5}$ $50 \%$ tissue culture infectious doses $/ \mathrm{ml}$. Levels of viral RNA copies $/ \mathrm{ml}$ were analyzed with the automated COBAS Amplicor System V1.5 (Roche Molecular Diagnostics). For the assay, $10 \mu \mathrm{l}$ of mouse sera were diluted to $500 \mu \mathrm{l}$ with sterile filtered normal human sera. The detection limit of the assay after dilution is 2500 viral RNA copies $/ \mathrm{ml}$.

Quantitative localized ${ }^{I} H$-magnetic resonance spectroscopy. Single voxel localized spectra were acquired using point resolved spectroscopy (PRESS) with outer volume suppression and high bandwidth pulses to optimize sequence performance. Acquisitions were acquired with a repetition time of $4 \mathrm{~s}$, echo time of $33 \mathrm{~ms}, 256$ averages, using volume coil transmit and surface coil receive on a 7 tesla/16 cm Bruker Pharmascan magnetic resonance imaging (MRI)/magnetic resonance spectroscopy (MRS) system. Single-scan-localized unsuppressed water signals were acquired as a reference for metabolite quantification. Spectroscopic data were processed by removal of residual water signal using the HLVSD filter. Spectra from ${ }^{1} \mathrm{H}$-MRS data sets were curve fitted in the time domain. Time domain analyses prevent the uncertainties associated with fitting the baseline to remove baseline intensity contributions to peak areas. Signals were fit in the time domain by the QUEST algorithm (Ratiney et al., 2004, 2005) using spectra (basis set) obtained from phantoms acquired by the same pulse sequence used during in vivo acquisition. Data for basis sets were used to calibrate signal intensities. These were normalized to water without correction for relaxation. Metabolite concentrations reported were semiquantitative. To preclude concentration corrections for relaxation, water normalized signal amplitudes were presented in institutional units (IU). IU approximates millimolar concentrations of metabolites.

Diffusion tensor imaging acquisition. Mice were anesthetized by inhalation of $1-2 \%$ isoflurane in a nitrous oxide/oxygen mixture, during MRI data acquisition. Diffusion tensor imaging (DTI) data were obtained using a 7 tesla/16 cm Bruker Pharmascan, an actively decoupled $72 \mathrm{~mm}$ volume coil transmitter and a laboratory built $1.25 \times 1.5 \mathrm{~cm}$ surface coil receiver. Reference coronal mouse brain images were obtained using three-dimensional FLASH with acquisition parameters of $24 \times 24 \times 16$ $\mathrm{mm}$ field of view, a $128 \times 128 \times 32$ matrix, $35^{\circ}$ flip angle, $50 \mathrm{~ms}$ repetition time (TR), 3 ms echo time (TE), and two averages for a total acquisition time of $7.5 \mathrm{~min}$. DTI data were acquired using single-shot diffusion-weighted spin-echo echo-planar imaging (TE, $43 \mathrm{~ms}$ ). Respiratory gating was used to prevent motion artifacts. Acquisition was repeated at TR of 10-15 s depending on respiratory rate and one shot per breath. Echo-planar imaging acquisition parameters included the following: 14 slices, $200 \mathrm{kHz}$ bandwidth, $96 \times 96$ in-plane acquisition zerofilled to $256 \times 256$, and a $0.5 \mathrm{~mm}$ slice thickness. The diffusion encoding used was a balanced, rotationally invariant, and alternating polarity icosahedral scheme (12 directions) (Boska et al., 2007). The encoding scheme was designed to reduce background-diffusion gradient coupling (Neeman et al., 1991a,b). Diffusion weighting $b$ factor $=800 \mathrm{~s} / \mathrm{mm}, d=$ $4 \mathrm{~ms}, D=15 \mathrm{~ms}, G_{\mathrm{dmax}}=40 \mathrm{G} / \mathrm{cm}, 200 \mathrm{~ms}$ rise time, seven averages for $b=0$ acquisition, three averages for each $b=800$ encoding direction, for a total acquisition time of $20-40 \mathrm{~min}$, depending on respiratory rate. Respiratory monitoring of animals, gating of the MRI system, and temperature monitoring of phantoms were done using an SA Instruments model 1025 MRI-compatible physiological monitoring system (model 1025; SA Instruments). Animal temperature control was maintained using a circulating water bath (Gaymar Industries) with heat exchange coils surrounding the mouse body on a custom-constructed MRI-compatible stereotactic mouse holder to immobilize the head. Water phantom studies using identical acquisition parameters and coils as the in vivo data were acquired monthly for quality assurance of instrument stability as well as to validate the lack of direct effect of HIV-1 on $D_{\text {av }}$ and fractional anisotropy (FA). Phantoms were chosen as they closely matched the coil loading of a mouse. Phantom temperature was monitored by the thermocouple of the MRI-compatible monitoring system (SA Instruments). These studies show consistent temperature-corrected $D_{\mathrm{av}}$ (mean $\pm \mathrm{SD}$, $2.29 \pm 0.30 \times 10^{-3} \mathrm{~mm}^{2} / \mathrm{s}$ at $\left.24^{\circ} \mathrm{C}\right)$ and low FA (0.065 \pm 0.035$)$.

Image analyses. Analyses of the diffusion-weighted data were performed using custom programs written in IDL as previously described (Basser et al., 1994a,b; Hassan et al., 2001). Analyses produced maps of the tensor diffusivities $\left(\lambda_{1}, \lambda_{2}, \lambda_{3}\right)$, average diffusivity $\left(D_{\text {av }}\right)$ where $D_{\text {av }}=$ $1 / 3^{\star}\left(\lambda_{1}+\lambda_{2}+\lambda_{3}\right)$, and FA. Transverse $\left(\lambda_{\perp}=\left(\lambda_{2}+\lambda_{3}\right) / 2\right)$ and longitudinal $\left(\lambda_{\|}=\lambda_{1}\right)$ components of the diffusion tensor were obtained as described (Hasan and Narayana, 2006).

Statistical analysis. Values of $D_{\mathrm{av}}, \mathrm{FA}, \lambda_{\perp}$, and $\lambda_{\|}$were acquired from both hemispheres of each mouse studied. The values from both regions of interest were averaged to arrive at the value of each variable as a single observation within each mouse, as paired $t$ test demonstrated no difference between results in the two hemispheres. Changes of FA, $D_{\mathrm{av}}, \lambda_{\perp}$, and $\lambda_{\|}$after infection were compared with preinfection values by an unpaired $t$ test as a preliminary analysis. Differences were considered significant at $p<0.05$. Statistical comparisons are performed using SPSS 14 (SPSS, Inc.).

Histopathological evaluation. Brains were perfused with PBS followed by $4 \%$ paraformaldehyde and then postfixed overnight and embedded in paraffin. Sections, $5 \mu \mathrm{m}$ thick, were cut from the paraffin blocks, mounted on glass slides, and labeled with mouse monoclonal antibodies (Dako) for HLA-DQ/DP/DR (clone CR3/43; 1:100), HIV-1 p24 (clone Kal-1; 1:10), and glial fibrillary acidic protein (GFAP) (1:1000). Microglia and macrophages were stained with rabbit polyclonal antibodies to ionized calcium binding adaptor molecule 1 (Iba-1) (1:500; Wako Chemicals). The polymer-based HRP-conjugated anti-mouse and antirabbit Dako EnVision systems were used as secondary detection reagents and developed with DAB (3,3'-diaminobenzidine). All paraffin-embedded sections were counterstained with Mayer's hematoxylin. Deletion of primary antibodies or mouse IgG served as controls. Images were obtained with a Nikon DS-Fil camera fixed to a Nikon Eclipse E800 (Nikon Instruments) using NIS-Elements F 3.0 software.

Immunofluorescence labeling, multispectral imaging, and image analyses. Slide specimens ( $5 \mu \mathrm{m}$ thick) of paraffin-embedded mouse brain were selected from the corresponding regions analyzed by DTI. Brain 
sections were treated with different paired combinations of primary mouse monoclonal antibodies to $200 \mathrm{kDa}$ plus $68 \mathrm{kDa}$ neurofilaments (NFs) (clone 2F11; 1:200; Dako) and synaptophysin (SYN) (1:1000; Novus Biologicals), and rabbit polyclonal antibodies to MAP2 and GFAP. Primary antibodies were labeled with secondary anti-mouse and antirabbit antibodies conjugated to the fluorescent probes Alexa Fluor 488 and Alexa Fluor 594, and nuclei were labeled with 4',6-diamidino2-phenylindole (DAPI). Slides were coverslipped with ProLong Gold anti-fade reagent (Invitrogen), allowed to dry for $24 \mathrm{~h}$ at room temperature, and then stored at $-20^{\circ} \mathrm{C}$ for future use. Images were captured at wavelengths encompassing the emission spectra of the probes, with a $20 \times$ objective. The fluorescence emission of each probe and autofluorescence of the tissue samples were analyzed by multispectral imaging/image analysis, with an automated fluorescence microscope (Leica DMRXA2; North Central Instruments), $\mathrm{Nu}-$ ance EX multispectral imaging system (Cambridge Research Instruments), and ImagePro Plus image analysis software (Media Cybernetics). These spectra were incorporated into a spectral unmixing algorithm (Nuance system) that quantitatively separated the grayscale images representing each spectral component. The grayscale images representing each fluorescent probe were exported from the Nuance system to the ImagePro Plus environment where fluorescent events, in brain regions of interest, were partitioned, and the fluorescence signal (same exposure times for controls and infected samples) was quantified as mean pixel intensity (12 bit grayscale) and total area (in square micrometers) of positive labeling. Area-weighted average fluorescence intensity was calculated for MAP2 and SYN expression by dividing the sum of the product of area and mean fluorescence intensity, for each partitioned area, by the sum of the partitioned areas. Fluorescence emission, across areas of hundreds of micrometers, were captured by wide-field microscopy. Loss of light due to light scatter at the perimeters was judged as negligible as partitions included areas of interest up to $200,000 \mu \mathrm{m}^{2}$ and individual events of $25-50 \mu \mathrm{m}^{2}$.

\section{Results}

Human cell reconstitution and HIV-1 infection of mice

Four humanized animals were monitored prospectively for numbers of $\mathrm{CD}^{+}{ }^{+}$and $\mathrm{CD} 8{ }^{+}$cells in circulation and, at the end point of observation, in spleen. At 22 weeks of age, mice were infected with HIV-1 ${ }_{\mathrm{ADA}}$ and viral load (VL) was assayed at 2, 4, 8, 12, and 15 weeks postinfection (wpi) (Fig. $1 A-D$ ); this was performed at the same time as MRS/DTI imaging. VL peaked at 4 weeks after viral infection and all infected animals had a sustained VL $(1.7 \times$ $10^{4}$ to $7.6 \times 10^{5} \mathrm{RNA}$ copies $\left./ \mathrm{ml}\right)$. The decline of $\mathrm{CD} 4^{+}$cells progressed rapidly because of disease between 8 and 15 weeks (Fig. $1 B$ ) but did not change in control noninfected mice observed over the same time period ( $n=30$ weeks) (Fig. $1 C$ ). The rapid decrease in the CD4 count during the course of infection, forced us to terminate the study at 15 wpi. The human cell profiles in the spleens of infected animals at the termination point were also analyzed (Fig. 1 E). Animals were stratified according to their immune status and peripheral VL. Animals m969 and $\mathrm{m} 973$ had 21.1 and $36.4 \%$ of $\mathrm{CD}^{+}{ }^{+} \mathrm{CD} 4{ }^{+}$cells in splenic lymphoid tissue, CD4:CD8 cell ratios of 1.0 and 0.8 (lower compared with
2:1-3:1 in uninfected animals), and peripheral VLs of $1.71 \times 10^{5}$ and $0.65 \times 10^{5}$ viral RNA copies $/ \mathrm{ml}$, respectively. They were considered less affected by HIV-1 infection compared with two other mice $\mathrm{m} 983$ and $\mathrm{m} 985$, which had higher VLs $\left(7.6 \times 10^{5}\right.$ and $4.81 \times 10^{5}$ viral RNA copies $\left./ \mathrm{ml}\right)$ and inverted CD4:CD8 ratios (0.1 and 0.4), and $\mathrm{m} 983$ had the lowest number $(3.4 \%)$ $\mathrm{CD} 3{ }^{+} \mathrm{CD} 4{ }^{+}$cells in spleen.

\section{Brain immunopathobiology}

Brain pathologies, which included influx of activated HLA-DR ${ }^{+}$ human cells, activation of microglial cells (Iba-1), and astrogliosis (GFAP) were determined by immunohistology of paraffinembedded 5- $\mu$ m-thick sections (Fig. 2). Brain regions including frontal cortex, whisker barrel (WB) somatosensory cortex (data not shown), cerebellum, corpus callosum, hippocampus, and brainstem were investigated. Mouse m983 (with highest VL and lowest $\mathrm{CD} 3{ }^{+} \mathrm{CD} 4{ }^{+}$cell percentage in spleen) had the most severe brain pathology. The presence of scattered lymphocytes in brain parenchyma, accumulation of human cells in meninges, and formation of perivascular cuffs around brain microvessels were found (Fig. 2). In the pons/medulla, activation of microglial cells with nodule formation not directly associated with human cell infiltration was noted. The same markers in control uninfected humanized mice of the same age group were analyzed, and the data of one representative mouse (m975) are shown in Figure 2. Based on the CD4 cell profiles, viral load profiles, and brain pathologies observed, the animals were grouped into two categories as severe brain pathology (m983 and m985) and moderate brain pathology (m969 and m973). 


\section{\begin{tabular}{|c|r}
\hline Cortex/Meninges & Brain stem \\
\hline
\end{tabular}}
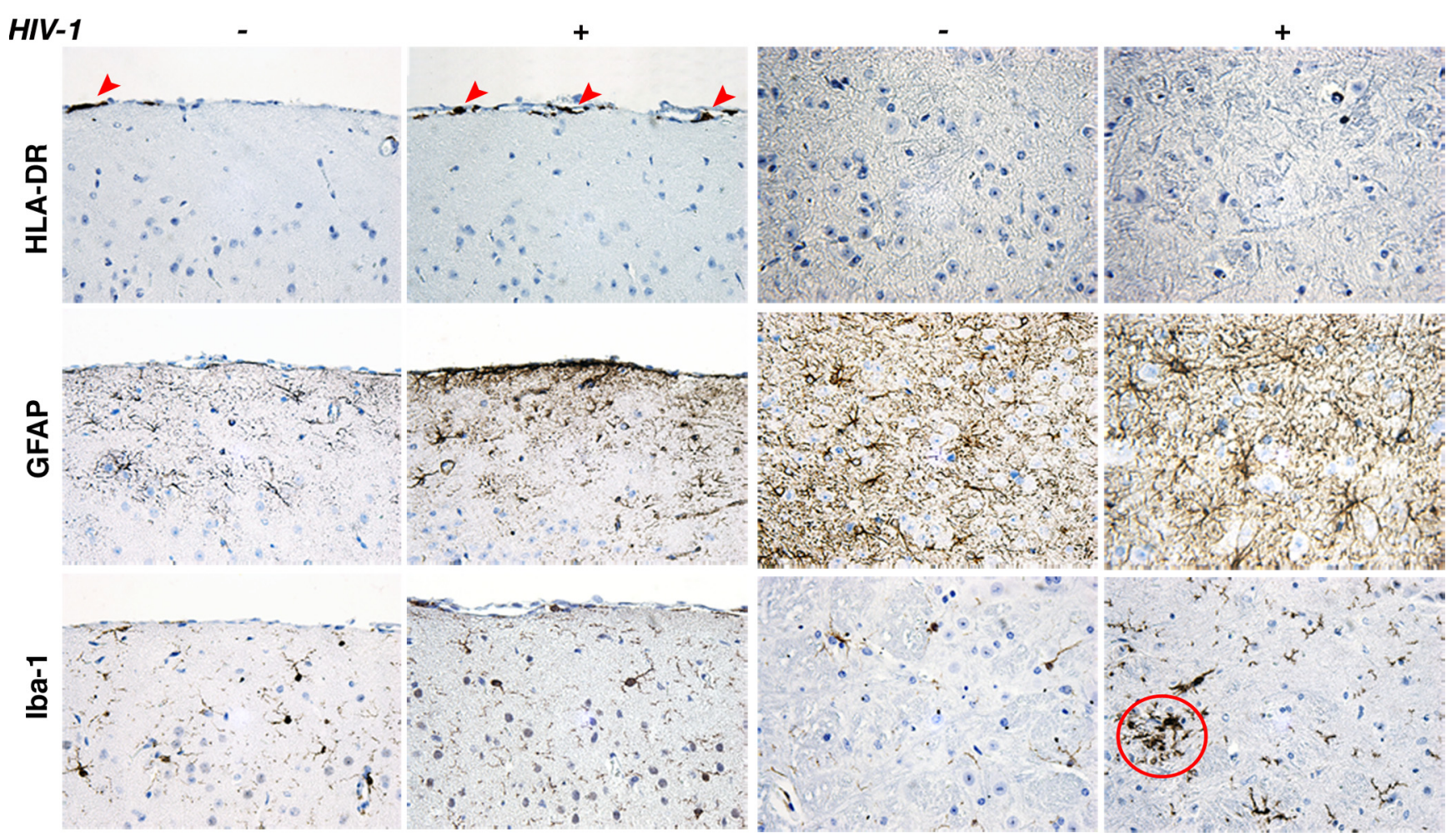

Figure 2. Histopathology of brain subregions. Representative brain regions in control uninfected (HIV-1 ${ }^{-}$) $\mathrm{m} 975$ and infected $\left(\mathrm{HIV}-1^{+}\right) \mathrm{m} 983$ animals. Paraffin sections $(5 \mu \mathrm{m})$ of brain were labeled with anti-HLA-DR to identify human activated cells, anti-lba-1 to detect macrophages and microglia, and anti-GFAP antibodies for astrocytes (all positive labeling is brown). Sections were counterstained with hematoxylin. Images of cortex, cerebellum, hippocampus, brainstem, and corpus collosum were captured with a $40 \times$ objective. Accumulation of human cells in meninges, perivascular spaces with activation of microglial cells (pons/medulla) and astrocytes (cortex, hippocampus, and pons/medulla) in infected mouse were noted. The arrows indicate perivascular cuff of HLA-DR ${ }^{+}$cells; red circle indicates microglial nodule formation.
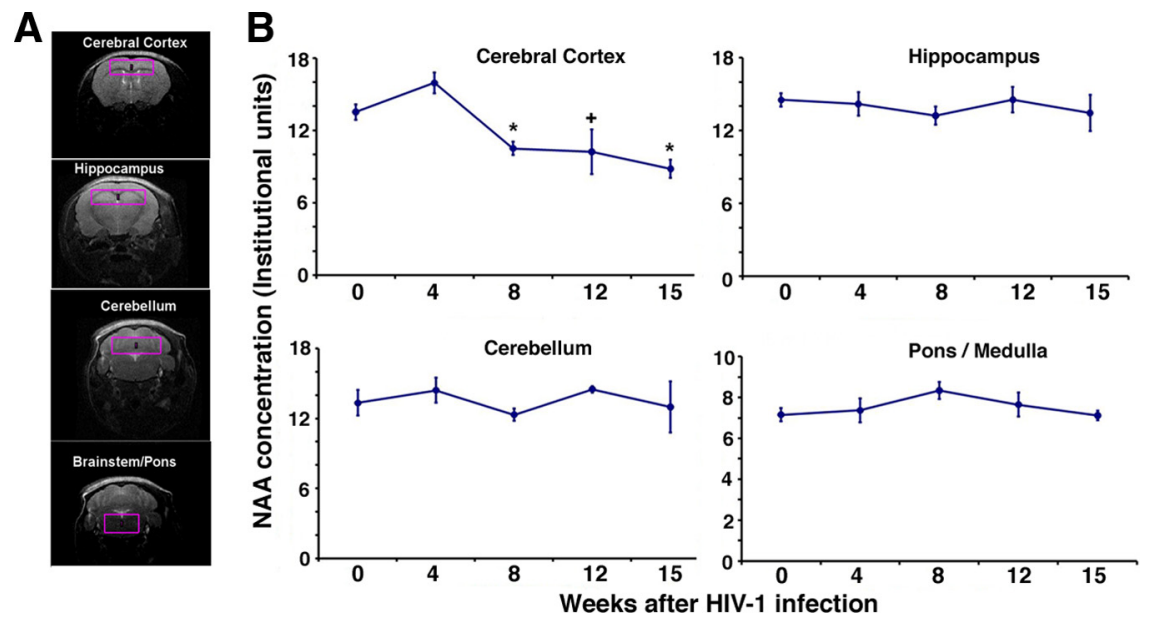

Figure 3. $\quad{ }^{1} \mathrm{H}-\mathrm{MRS}$ analyses. $\boldsymbol{A}$, Brain regions of interests. $\boldsymbol{B}, \mathrm{N}$-Acetyl aspartate concentrations in HIV-1-infected humanized mice. The means \pm SEMs of $[N A A]$ from selected regions of brain are shown. The values were normalized to water for quantitative assessment. The values were drawn at ${ }^{*} p<0.05$ versus preinfection and ${ }^{+} p<0.1$ versus preinfection. It can be clearly seen that NAA is significantly reduced over the course of infection in the cerebral cortex but not in the cerebellum, hippocampus, or brainstem/pons region.

\section{${ }^{1} \mathrm{H}-\mathrm{MRS}$ measures}

${ }^{1} \mathrm{H}-\mathrm{MRS}$ tests were used to determine whether changes in neuronal integrity could be present. These results were validated by immunocytochemical tests for neuronal integrity. The regions selected for spectroscopic examination using the PRESS volume selective spec- troscopic acquisitions included cerebral cortex, hippocampus, cerebellum, and brainstem/pons (Fig. 3A). ${ }^{1} \mathrm{H}$-MRS was collected from four humanized NSG mice at different time points $(0,4,8,12$, and 15 weeks after infection with HIV). Preinfection reconstituted (time, 0 weeks), unmanipulated humanized NSG mice aged 3 months $(n=5)$, and NSG mice aged 6 months $(n=3)$, showed no significant differences in $\mathrm{N}$-acetyl aspartate (NAA) concentrations among the different brain regions studied (data not shown). The NAA concentration of uninfected mice of equivalent age (36 weeks) and time (equal to 15 weeks after infection) was $10-12$ IU as measured in the cerebral cortex. The nervous system-specific metabolite NAA, which is synthesized in neurons and appears to be a key link in distinct biochemical features of CNS metabolism, was measured at the time points described above. The means \pm SEMs of NAA concentration normalized to water for quantitative assessments are presented in Figure 3B. It can be clearly seen that NAA is significantly reduced over the course of infection in the cerebral cortex (Fig. $3 B$ ) but not in the cerebellum, hippocampus, or brainstem/ pons regions. Moreover, one mouse (m983) showed a substantial 
A

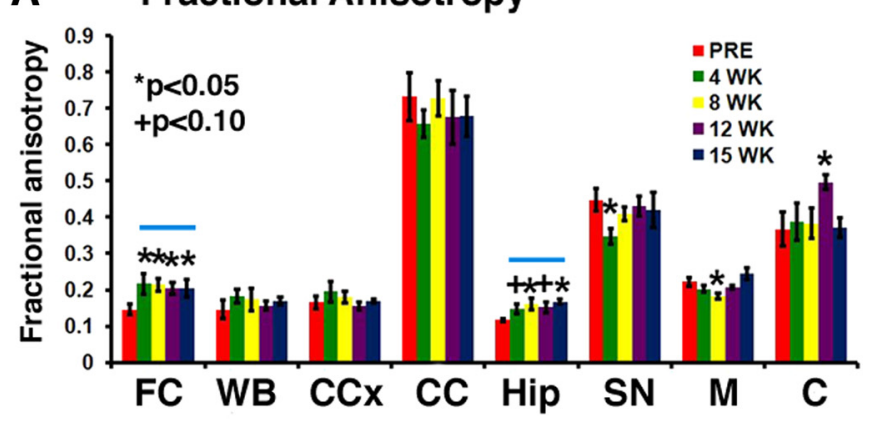

C

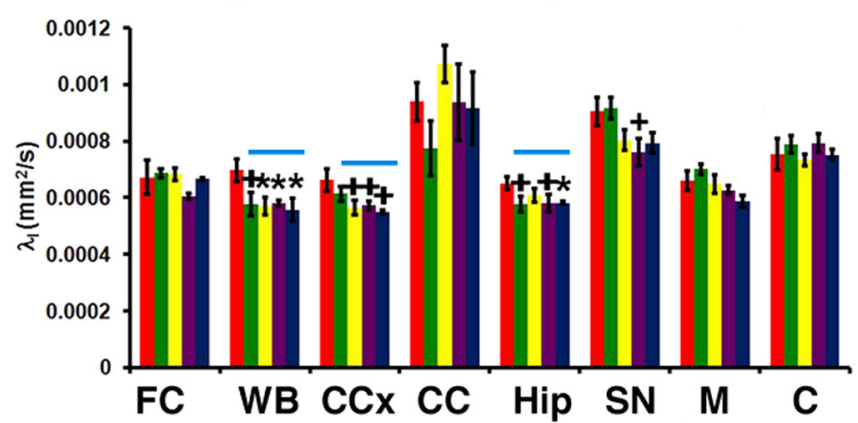

E

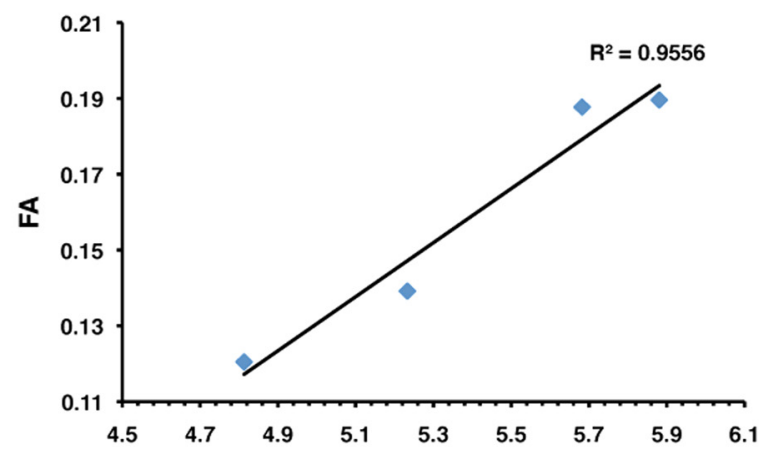

G

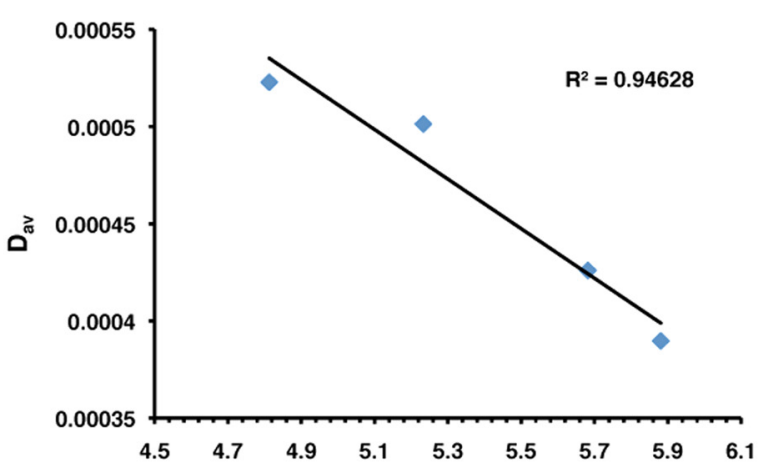

$\mathrm{VL}, \log 10$ copies $/ \mathrm{ml}$
B Mean Diffusivity

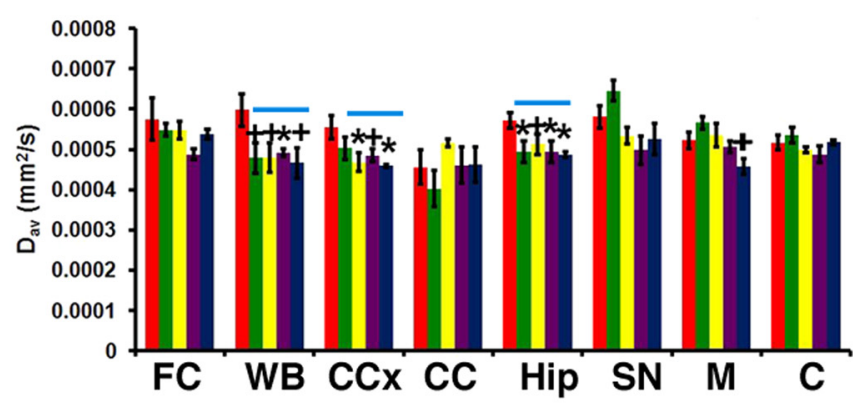

D Transverse Diffusivity

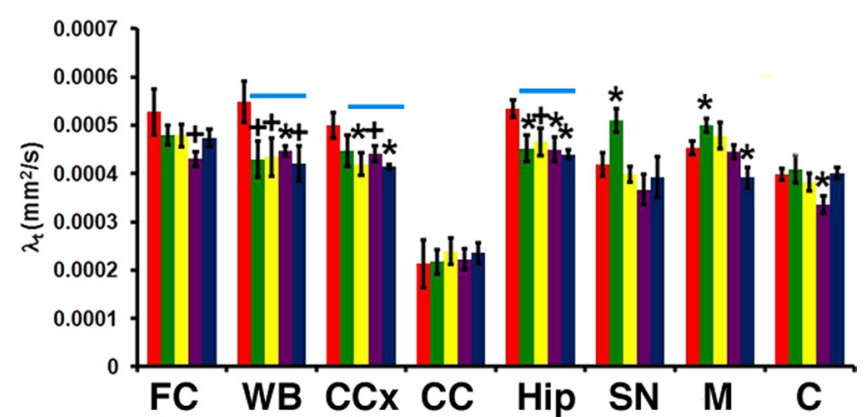

$\mathbf{F}$

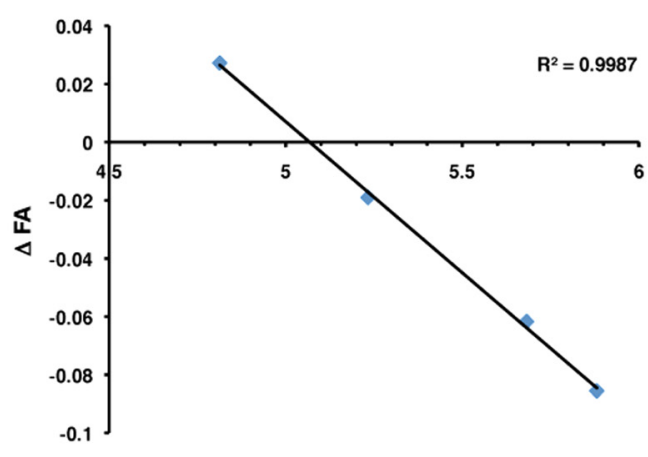

H

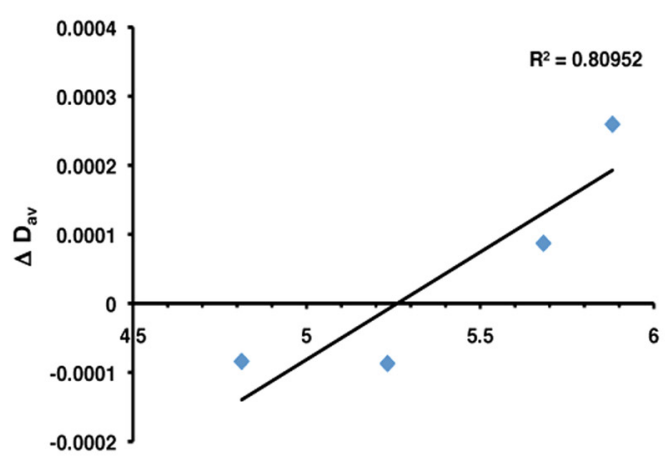

$\mathrm{VL}, \log 10$ copies/ml

Figure 4. DTI tests. $\boldsymbol{A}$, Fractional anisotropy $(F A)$. $\boldsymbol{B}$, Mean diffusivity $\left(D_{\text {av }}\right)$. C , Longitudinal diffusivity $\left(\lambda_{\|}\right)$. $\boldsymbol{D}$, Transverse diffusivity $\left(\lambda_{\perp}\right)$. Notable and consistent changes include increased FA in the frontal cortex (FC) and hippocampus (Hip), as well as decreased diffusivity in the whisker barrels (WB), cerebral cortex (CCX), and hippocampus of humanized mice group with more severe brain pathology. Statistically significant changes were not observed in the corpus callosum (CC), substantia nigra (SN), medulla (M), and cerebellum (C). $\boldsymbol{E}, \boldsymbol{G}$, Correlation analyses of endpoint viral load with endpoint DTI metrics (FA and Dav) in WB. $\boldsymbol{F}, \boldsymbol{H}$, Correlation analysis of magnitude of changes of DTI metrics $(\Delta)$ before and after HIV infection with viral load in WB region. 
MAP-2/SYN/DAPI
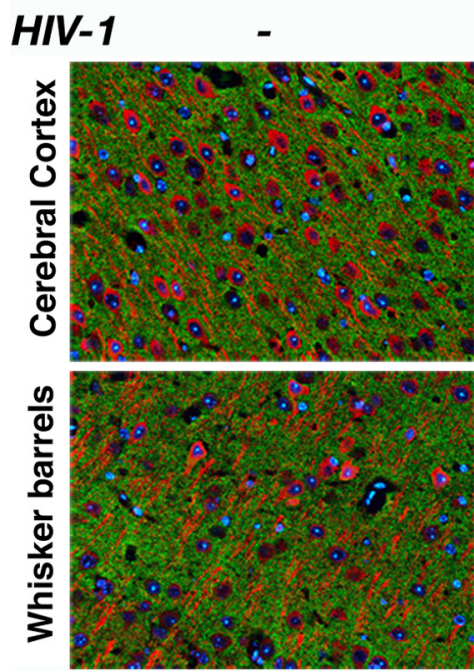
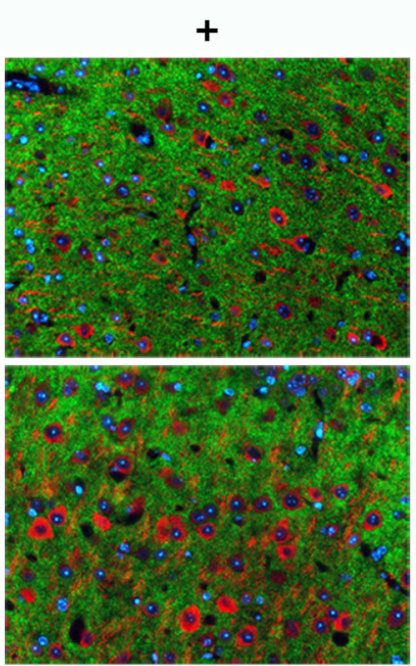

GFAP/NF/DAPI
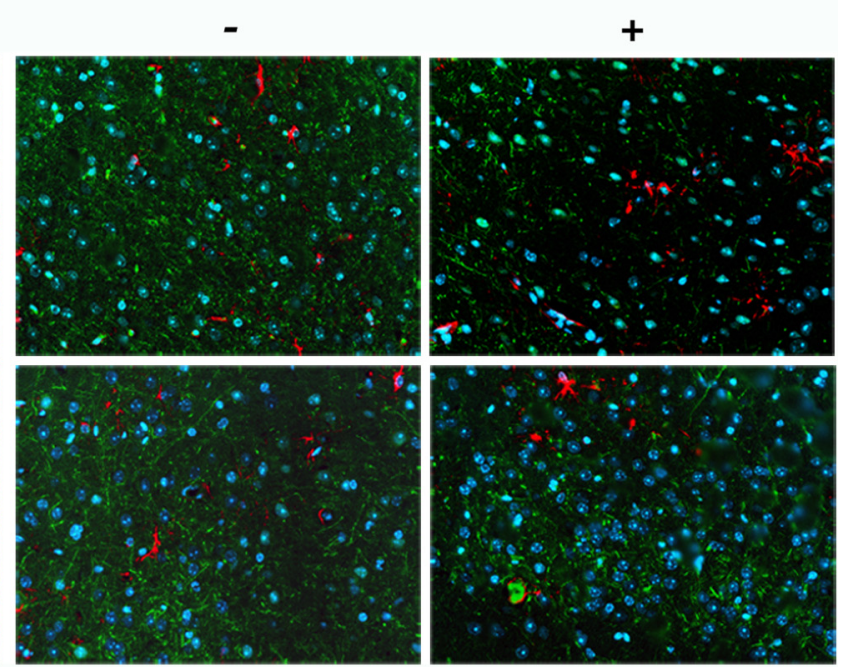

Figure 5. Immunofluorescence labeling of astrocytes, neurofilaments, and synapses in brain regions of both HIV-infected and noninfected CD34-NSG mice. Slide-mounted sections (5 $\mu$ m) of brain from a noninfected mouse with the least brain damage (control m975) and an infected mouse with a markedly elevated viral load and exhibiting the most brain damage (m983) were stained for GFAP (an astrocyte-specific marker; red) and Neurofilament (green). Images of cerebral cortex, whisker barrel, and brainstem were captured at $40 \times$ objective. Dendritic and synaptic morphology of cortical neurons are illustrated. Sections of mouse m 975 and mouse $m 983$ were labeled for MAP2 (red), Synaptophysin (green), and nuclei (DAPI; blue). The panels to the far left map tissue labeling to regions in the context of whole-brain sections.

reduction in NAA in the cerebellum (NAA, 6.85 IU) at the 15 wpi. As NAA is commonly presented as a ratio to creatine, we compared NAA levels normalized to creatine or to water. Both measures were nearly identical. Creatine remains constant over time in the animals (data not shown). Hence, presentation of NAA as either concentrations or metabolite ratios to creatine provides equivalent results in the animals.

\section{DTI tests}

The DTI measures for FA reflect changes of the tissue organization at a microscopic level by measuring water diffusion in different directions, which changes as a consequence of structural neuronal geometry. DTI examinations were performed over the same time period as ${ }^{1} \mathrm{H}$-MRS measurements. DTI results from the selected regions measured bilaterally from the four animals were divided based on peripheral immune status, VL, and brain immunopathology analyzed independently. Results from the severely affected mice (m983 and m985) are presented in Figure 4. Notable and consistent changes include increased FA in the frontal cortex and hippocampus as well as decreased $D_{\mathrm{av}}, \lambda_{\|}$, and $\lambda_{\perp}$ in the WB along with other cortical areas and hippocampus. Multiple gray matter regions show statistically significant changes over the course of disease development, more than were found from moderately affected mice $\mathrm{m} 969$ and $\mathrm{m} 973$ (data not shown). In the WB, there was a strong linear correlation between VL and FA, specifically when correlated magnitude of FA increase $(\Delta)$ from preinfection to $15 \mathrm{wpi}\left(R^{2}=0.9987\right)$. The same strong trends were found for decline of $D_{\mathrm{av}}$ diffusivity (Fig. $4 E, F$ ). Similar correlations of FA and VL were observed in the pons/medulla $\left(R^{2}=-0.9811\right)$ (data not shown).

\section{Quantitative multispectral fluorescence microscopy}

To determine whether in vivo reduction of NAA concentration detected by ${ }^{1} \mathrm{H}-\mathrm{MRS}$ and changes in DTI values correspond to changes of brain architecture, at termination of the experiment, immunofluorescence neuronal and glial antigens were analyzed by multispectral fluorescence microscopy of replicate brain regions. The images captured with the Nuance multispectral imag- ing system $(20 \times$ objective) were converted to 12 bit grayscale images and quantified using ImagePro Plus software. Representative images of the labeled neuronal markers captured $(40 \times$ objective) with the Nuance multispectral imaging system are presented in Figure 5. The cortical neurons of control animals showed normal MAP2-immunolabeled dendrites, whereas the HIV-1-infected humanized mice showed decreased expression of MAP2-immunolabeled dendrites with irregular and wavy contours. SYN labeling in cortical areas of control animals was observed as diffusely punctate, whereas SYN expression was irregularly shaped in all infected animals. Reduction of NFpositive fibers was observed in the cortex of animals with significant immune and brain pathology (m983 and m985) compared with less affected (m969 and m973) and control animals. In WB of all infected animals, the amount of NF was significantly reduced (Fig. 5). However, in the pons/medulla, these changes were not as significant as seen in cortex and WB (Fig. 5, bottom right panel)

For MAP2 and SYN, the quantitative data were expressed as total positive area/total area analyzed in square micrometers and their corresponding mean pixel density intensity (Fig. 6). For NF and GFAP, data were expressed as total area labeled. There was a diminution in the cerebral cortex and WB of MAP2 and SYN levels compared with uninfected animal but not in the pons/ medulla. The most dramatic reduction of NF labeling was found in WB (Fig. 6). Observed changes allowed us to suggest that in addition to dendritic/synaptic protein aberrations, the damage represented by NF also contributed to the changes of [NAA] and MRI/DTI metrics.

\section{Discussion}

HIV-1-associated neuropathology seen during progressive viral infection of humanized CD34-NSG mice was linked to systemic viral infection. The sequence of events consisted of viral invasion of the nervous system, glial neuroinflammatory responses, and neurodegeneration. Early development of aseptic meningitis and $\mathrm{CD}^{+}{ }^{+}$T-lymphocyte depletion was also observed, as reported 
A
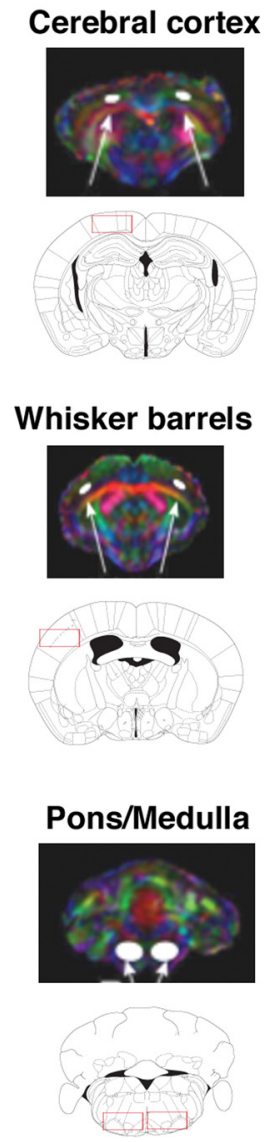

B

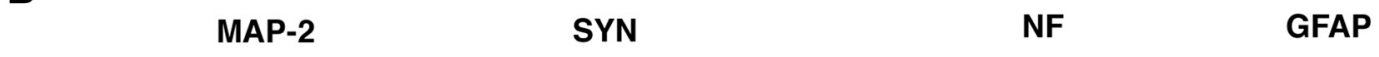

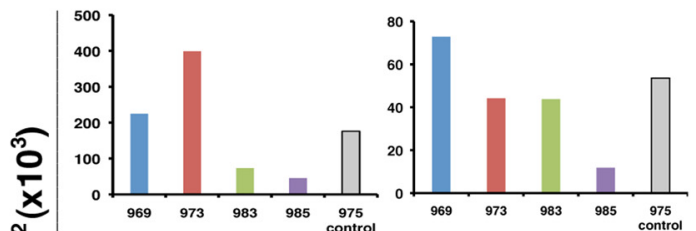

बٓ
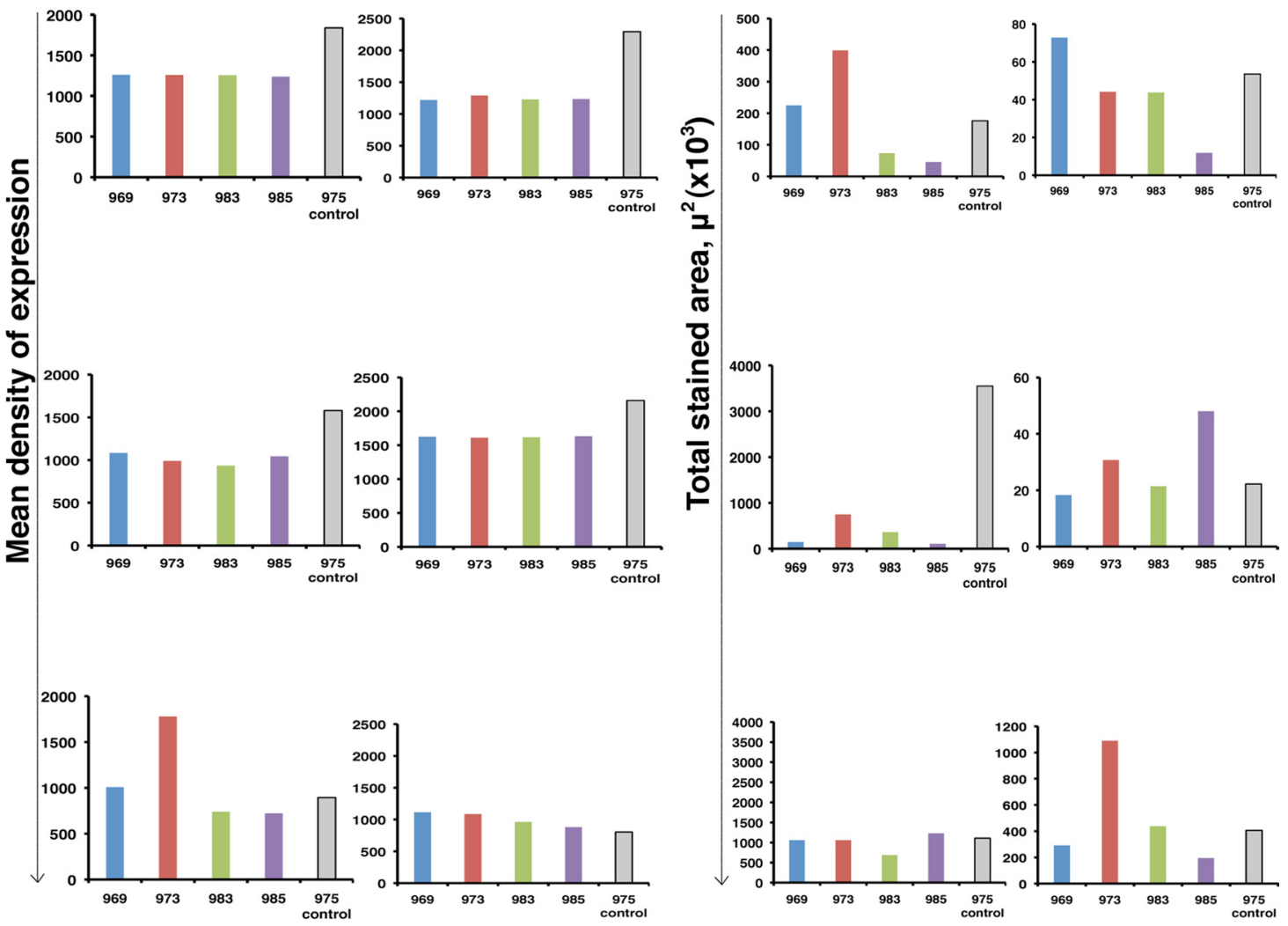

Mouse number

Figure 6. Quantitative fluorescence microscopy of neuronal protein expressions in brains of CD34-NSG mice. A, Schematic representation of the strategy of analysis. Slide-mounted brain sections ( $5 \mu \mathrm{m}$ thick) that included the corresponding regions (mouse brain atlas) analyzed by DTI were analyzed by quantitative fluorescence microscopy with an automated fluorescence microscope (Leica), multispectral imaging system (Nuance EX), and ImagePro Plus image analysis software. Image cubes consisting of a Z-stack of images over a wide range of wavelengths were captured from each microscope field with a $20 \times$ objective. Cubes were unmixed by spectra corresponding to each fluorescence label and to autofluorescence into quantitative grayscale images for analysis of intensity and area of fluorescence emission. $\boldsymbol{B}$, Individual mouse data represent expression of the neuronal proteins MAP2 and SYN (fluorescence intensity) and NF and GFAP (area of positive fluorescence labeling). The reduction of MAP2 and SYN were detected in cortical regions, but not in pons/medulla. The significant drop of NF was found in WB in all analyzed mice and in frontal cortex of two mice with significant immune pathology (m983, $\mathrm{m} 985$ ). It was not clearly observed in pons/medulla region. Variable changes in GFAP-labeled areas were noted for different regions.

(Gorantla et al., 2007, 2010a,b). After the initiation of viral infection, development of neuronal abnormalities in cerebral cortex were seen in the animals for up to 15 weeks by spectroscopic and diffusion tensor imaging and confirmed by immunohistological tests. These revealed decreased expression of SYN, an integral protein in presynaptic terminals, and MAP2, a marker for neuronal cell bodies and dendrites, and axonal NF in cerebral cortex. Such changes reflect substantive neurodegeneration and are also found in the brains of HIV-1-infected individuals.

Human neuropathology was previously studied in some depth during the later stages of viral infection in the absence of combination antiretroviral therapy. This is where encephalitis was commonly seen and was a result of virus-infected mononuclear phagocytes (blood-derived perivascular macrophages and microglia) and formation of multinucleated giant cells, astrogliosis, myelin pallor, and neuronal morphological changes. The latter was seen as decreased synaptic density and neuronal dropout (Price et al., 1988; Budka, 1991; Gelman, 1993; Wiley, 1995; Kraft-Terry et al., 2009). These morphological features of HIV1 -induced neurodegeneration have diminished in severity as a consequence of antiretroviral medicines (Masliah et al., 1996; Everall et al., 1999; Zheng et al., 2001; McCarthy et al., 2006).
In recent years, clinical investigators have used MRS and DTI to assess the underlying basis for cognitive dysfunction during progressive HIV-1 infection in its human host (Pomara et al., 2001; Lim and Helpern, 2002; Schifitto et al., 2009; MüllerOehring et al., 2010). In the present study, we used both ${ }^{1} \mathrm{H}-\mathrm{MRS}$ and DTI, to monitor biochemical and structural alterations, respectively, in brain regions during the progression of HIV infection in humanized mice. Our ${ }^{1} \mathrm{H}$-MRS tests showed significant decreases in NAA concentration in cerebral cortex. NAA, the most abundant neuron-specific metabolite reflects the degree of neuronal injury (Chong et al., 1994; Meyerhoff et al., 1994; Laubenberger et al., 1996; Simone et al., 1998; Moffett et al., 2007). Moreover, NAA concentration is often used as a marker of neuronal viability in a range of neurodegenerative disorders that includes HAND, Alzheimer's disease, epilepsy, multiple sclerosis, and spinal cord injury (Meyerhoff et al., 1993, 1994; Marcus et al., 1998; Suwanwelaa et al., 2000; Tarasów et al., 2003; Chang et al., 2004; Soares and Law, 2009; Mohamed et al., 2010). Reductions in NAA were also seen in ${ }^{1} \mathrm{H}$-MRS studies of SIV-infected monkeys (Lentz et al., 2005, 2008a,b; Ratai et al., 2009). Although previous studies showed changes in NAA concentrations as reflective of human cognitive impairment, their use has been ham- 
pered by variations in levels over time, comorbid conditions, and the inability to coregister histopathological correlates of affected brain regions. The decrease in NAA concentration in the cerebral cortex occurred in all four HIV-1-infected humanized mice and correlated with diminution of MAP2, SYN expression. However, in two mice with the highest levels of viral infection (m983 and m985), NF expression was also reduced. In contrast, astrogliosis, as measured by GFAP expression, was not uniformly altered. The diminished NAA concentration, seen in the cortex of the HIV-1infected humanized mice, may not be directly related to neuronal apoptosis but rather may be an indicator of neuronal abnormalities and is supported by the findings that the biosynthetic enzyme for NAA, $N$-acetyl transferase, is localized in neuronal mitochondria and synaptosomal cell fractions (Moffett et al., 2007). More work certainly remains to be done to quantify the extent of neuronal damage and validate biomarkers of virusassociated neurodegenerative disease in this model system.

In addition to biochemical changes, we found structural brain tissue alterations by DTI. We observed an increase of FA and a decrease of diffusivity in several gray matter regions starting 4 wpi in animals with higher viral load and established immunopathology. DTI can assess displacement of water on the micrometer scale, yielding information about white matter fiber integrity (Takahashi et al., 2000; Assaf and Pasternak, 2008; Y. Chen et al., 2009; Gongvatana et al., 2009) as well as gray matter during CNS development (McKinstry et al., 2002; Mukherjee et al., 2002; Mukherjee and McKinstry, 2006; Neil and Inder, 2006; Yassa et al., 2010) and neurodegeneration such as Alzheimer's disease (Head et al., 2004; Rose et al., 2008; T. F. Chen et al., 2009; Cherubini et al., 2010; Kantarci et al., 2010; Sexton et al., 2010). FA is highly sensitive to microstructural changes but is not very specific to the type of changes. If in the developing brain a decrease in FA represents ongoing establishment of cortical neuronal interconnectivity, then in earlier stages of HIV-1 infection in humanized mice the changes observed could be associated with structural alteration of synaptic and dendritic processes. The reduction in expression of MAP2 and SYN and the abnormal appearance of SYN-positive structures in the cortex support our findings of FA and diffusivity values.

We also systematically studied, and in replicate manner to the bioimaging and histopathological tests, cognitive and sensorimotor functions studying NSG mice. Others' and our previous experiences in short-term rodent models of HIV-1 encephalitis were founded on Morris water maze testing (Avgeropoulos et al., 1998; Zink et al., 2002) and a water escape radial arm maze test series (Sas et al., 2007). In these works, cognitive deficits (spatial memory development and retention) were shown as was seen in aged HIV-1 gp120 transgenic mice (D'Hooge et al., 1999). However, water maze could not be easily used for our current model as NSG animals are substantively immunologically impaired and any exposure to cold water significantly increases the risk of infection and subsequent death of the animal. To overcome such impediments and to test learning and memory, we selected the Barnes circular platform task (Markowska et al., 1989). This system was used to perform several basic testing. We found that NSG mice had gender-dependent differences as males had significantly increased exploratory behavior on the platform compared with females. We also observed age-dependent decline in learning and memory in 12-month-old compared with 6-month-old males. We then compared learning and memory in unmanipulated versus animals irradiated at birth. Here, females were reconstituted at 6 months of age. The unmanipulated and irradiated/ reconstituted mice did not show statistically significant differences in cognition (our unpublished observations) and suggested that such an approach would not readily yield changes in learning and memory after HIV infection. Currently, we are in the process of standardizing tests for behavioral testing in this unique model.

The only other animal system that shows the changes observed herein in humanized mice is the SIV-infected rhesus macaque (Bissel et al., 2002; Lentz et al., 2005; Scheller et al., 2005; Thompson et al., 2009). Importantly, and also operative in SIVinfected monkeys, few numbers of virus-infected and immunecompetent perivascular mononuclear phagocytes can affect widespread neuronal dysfunction (Williams et al., 2001, 2005; Marcario et al., 2004; Crews et al., 2008). Nonetheless, expense and species specificity preclude the widespread use of SIV models for the study of the early stages of infection. Thus, relevant rodent models that mimic human disease are sorely needed. To our knowledge, this is the first report to show associations between ${ }^{1} \mathrm{H}$-MRS and DTI evidence of deficits in neuronal integrity. These deficits were confirmed by immunohistochemical evaluation. This study highlights the relevance of humanized mouse models for research on the pathobiology of human disease and underlies the future applications of noninvasively monitoring the systemic effects of antiretrovirals and adjunctive therapeutics.

\section{References}

Antinori A, Arendt G, Becker JT, Brew BJ, Byrd DA, Cherner M, Clifford DB, Cinque P, Epstein LG, Goodkin K, Gisslen M, Grant I, Heaton RK, Joseph J, Marder K, Marra CM, McArthur JC, Nunn M, Price RW, Pulliam L, et al. (2007) Updated research nosology for HIV-associated neurocognitive disorders. Neurology 69:1789-1799.

Assaf Y, Pasternak O (2008) Diffusion tensor imaging (DTI)-based white matter mapping in brain research: a review. J Mol Neurosci 34:51-61.

Atwood WJ, Berger JR, Kaderman R, Tornatore CS, Major EO (1993) Human immunodeficiency virus type 1 infection of the brain. Clin Microbiol Rev 6:339-366.

Avgeropoulos N, Kelley B, Middaugh L, Arrigo S, Persidsky Y, Gendelman HE, Tyor WR (1998) SCID mice with HIV encephalitis develop behavioral abnormalities. J Acquir Immune Defic Syndr Hum Retrovirol 18:13-20.

Basser PJ, Mattiello J, LeBihan D (1994a) MR diffusion tensor spectroscopy and imaging. Biophys J 66:259-267.

Basser PJ, Mattiello J, LeBihan D (1994b) Estimation of the effective selfdiffusion tensor from the NMR spin echo. J Magn Reson B 103:247-254.

Bissel SJ, Wang G, Ghosh M, Reinhart TA, Capuano S 3rd, Stefano Cole K, Murphey-Corb M, Piatak M Jr, Lifson JD, Wiley CA (2002) Macrophages relate presynaptic and postsynaptic damage in simian immunodeficiency virus encephalitis. Am J Pathol 160:927-941.

Boska MD, Hasan KM, Kibuule D, Banerjee R, McIntyre E, Nelson JA, Hahn T, Gendelman HE, Mosley RL (2007) Quantitative diffusion tensor imaging detects dopaminergic neuronal degeneration in a murine model of Parkinson's disease. Neurobiol Dis 26:590-596.

Boufassa F, Bachmeyer C, Carré N, Deveau C, Persoz A, Jadand C, Séréni D, Bucquet D (1995) Influence of neurologic manifestations of primary human immunodeficiency virus infection on disease progression. SEROCO Study Group. J Infect Dis 171:1190-1195.

Budka H (1991) Neuropathology of human immunodeficiency virus infection. Brain Pathol 1:163-175.

Chang L, Lee PL, Yiannoutsos CT, Ernst T, Marra CM, Richards T, Kolson D, Schifitto G, Jarvik JG, Miller EN, Lenkinski R, Gonzalez G, Navia BA (2004) A multicenter in vivo proton-MRS study of HIV-associated dementia and its relationship to age. Neuroimage 23:1336-1347.

Chen TF, Chen YF, Cheng TW, Hua MS, Liu HM, Chiu MJ (2009) Executive dysfunction and periventricular diffusion tensor changes in amnesic mild cognitive impairment and early Alzheimer's disease. Hum Brain Mapp 30:3826-3836.

Chen Y, An H, Zhu H, Stone T, Smith JK, Hall C, Bullitt E, Shen D, Lin W (2009) White matter abnormalities revealed by diffusion tensor imaging in non-demented and demented $\mathrm{HIV}^{+}$patients. Neuroimage 47:1154-1162. 
Cherubini A, Péran P, Spoletini I, Di Paola M, Di Iulio F, Hagberg GE, Sancesario G, Gianni W, Bossù P, Caltagirone C, Sabatini U, Spalletta G (2010) Combined volumetry and DTI in subcortical structures of mild cognitive impairment and Alzheimer's disease patients. J Alzheimers Dis 19:1273-1282.

Chong WK, Paley M, Wilkinson ID, Hall-Craggs MA, Sweeney B, Harrison MJ, Miller RF, Kendall BE (1994) Localized cerebral proton MR spectroscopy in HIV infection and AIDS. AJNR Am J Neuroradiol 15:21-25.

Crews L, Lentz MR, Gonzalez RG, Fox HS, Masliah E (2008) Neuronal injury in simian immunodeficiency virus and other animal models of neuroAIDS. J Neurovirol 14:327-339.

Davis LE, Hjelle BL, Miller VE, Palmer DL, Llewellyn AL, Merlin TL, Young SA, Mills RG, Wachsman W, Wiley CA (1992) Early viral brain invasion in iatrogenic human immunodeficiency virus infection. Neurology 42:1736-1739.

del Saz SV, Sued O, Falcó V, Agüero F, Crespo M, Pumarola T, Curran A, Gatell JM, Pahissa A, Miró JM, Ribera E (2008) Acute meningoencephalitis due to human immunodeficiency virus type 1 infection in 13 patients: clinical description and follow-up. J Neurovirol 14:474-479.

D’Hooge R, Franck F, Mucke L, De Deyn PP (1999) Age-related behavioural deficits in transgenic mice expressing the HIV-1 coat protein gp120. Eur J Neurosci 11:4398-4402.

Everall IP, Heaton RK, Marcotte TD, Ellis RJ, McCutchan JA, Atkinson JH, Grant I, Mallory M, Masliah E (1999) Cortical synaptic density is reduced in mild to moderate human immunodeficiency virus neurocognitive disorder. HNRC Group. HIV Neurobehavioral Research Center. Brain Pathol 9:209-217.

Gelman BB (1993) Diffuse microgliosis associated with cerebral atrophy in the acquired immunodeficiency syndrome. Ann Neurol 34:65-70.

Gongvatana A, Schweinsburg BC, Taylor MJ, Theilmann RJ, Letendre SL, Alhassoon OM, Jacobus J, Woods SP, Jernigan TL, Ellis RJ, Frank LR, Grant I (2009) White matter tract injury and cognitive impairment in human immunodeficiency virus-infected individuals. J Neurovirol 15:187-195.

Gorantla S, Sneller H, Walters L, Sharp JG, Pirruccello SJ, West JT, Wood C, Dewhurst S, Gendelman HE, Poluektova L (2007) Human immunodeficiency virus type 1 pathobiology studied in humanized BALB/ c-Rag2 ${ }^{-1-} \gamma_{\mathrm{c}}{ }^{-1-}$ mice. J Virol 81:2700-2712.

Gorantla S, Makarov E, Finke-Dwyer J, Gebhart CL, Domm W, Dewhurst S, Gendelman HE, Poluektova LY (2010a) $\mathrm{CD}^{+}$cell depletion accelerates HIV-1 immunopathology in humanized mice. J Immunol 184:70827091.

Gorantla S, Makarov E, Finke-Dwyer J, Castanedo A, Holguin A, Gebhart C, Gendelman H, Poluektova L (2010b) Links between progressive HIV-1 infection of humanized mice and viral neuropathogenesis. Am J Pathol 177:2938-2949.

Gray F, Scaravilli F, Everall I, Chretien F, An S, Boche D, Adle-Biassette H, Wingertsmann L, Durigon M, Hurtrel B, Chiodi F, Bell J, Lantos P (1996) Neuropathology of early HIV-1 infection. Brain Pathol 6:1-15.

Hasan KM, Narayana PA (2006) Retrospective measurement of the diffusion tensor eigenvalues from diffusion anisotropy and mean diffusivity in DTI. Magn Reson Med 56:130-137.

Hassan N, Olivier P, Marie PY, Danchin N, Karcher G, Bertrand A (2001) Use of gated SPECT to identify a case in which tracer activity arising from the right ventricular free wall led to overestimation of the amount of viability within the septal wall. J Nucl Cardiol 8:630-631.

Head D, Buckner RL, Shimony JS, Williams LE, Akbudak E, Conturo TE, McAvoy M, Morris JC, Snyder AZ (2004) Differential vulnerability of anterior white matter in nondemented aging with minimal acceleration in dementia of the Alzheimer type: evidence from diffusion tensor imaging. Cereb Cortex 14:410-423.

Horn TF, Huitron-Resendiz S, Weed MR, Henriksen SJ, Fox HS (1998) Early physiological abnormalities after simian immunodeficiency virus infection. Proc Natl Acad Sci U S A 95:15072-15077.

Kantarci K, Avula R, Senjem ML, Samikoglu AR, Zhang B, Weigand SD, Przybelski SA, Edmonson HA, Vemuri P, Knopman DS, Ferman TJ, Boeve BF, Petersen RC, Jack CR Jr (2010) Dementia with Lewy bodies and Alzheimer disease: neurodegenerative patterns characterized by DTI. Neurology 74:1814-1821.

Kim BO, Liu Y, Ruan Y, Xu ZC, Schantz L, He JJ (2003) Neuropathologies in transgenic mice expressing human immunodeficiency virus type 1 Tat protein under the regulation of the astrocyte-specific glial fibrillary acidic protein promoter and doxycycline. Am J Pathol 162:1693-1707.

Kraft-Terry SD, Buch SJ, Fox HS, Gendelman HE (2009) A coat of many colors: neuroimmune crosstalk in human immunodeficiency virus infection. Neuron 64:133-145.

Lackner AA, Smith MO, Munn RJ, Martfeld DJ, Gardner MB, Marx PA, Dandekar S (1991) Localization of simian immunodeficiency virus in the central nervous system of rhesus monkeys. Am J Pathol 139:609-621.

Laubenberger J, Häussinger D, Bayer S, Thielemann S, Schneider B, Mundinger A, Hennig J, Langer M (1996) HIV-related metabolic abnormalities in the brain: depiction with proton MR spectroscopy with short echo times. Radiology 199:805-810.

Lentz MR, Kim JP, Westmoreland SV, Greco JB, Fuller RA, Ratai EM, He J, Sehgal PK, Halpern EF, Lackner AA, Masliah E, González RG (2005) Quantitative neuropathologic correlates of changes in ratio of $\mathrm{N}$-acetylaspartate to creatine in macaque brain. Radiology 235:461-468.

Lentz MR, Westmoreland SV, Lee V, Ratai EM, Halpern EF, González RG (2008a) Metabolic markers of neuronal injury correlate with SIV CNS disease severity and inoculum in the macaque model of neuroAIDS. Magn Reson Med 59:475-484.

Lentz MR, Lee V, Westmoreland SV, Ratai EM, Halpern EF, González RG (2008b) Factor analysis reveals differences in brain metabolism in macaques with SIV/AIDS and those with SIV-induced encephalitis. NMR Biomed 21:878-887.

Lim KO, Helpern JA (2002) Neuropsychiatric applications of DTI-a review. NMR Biomed 15:587-593.

Marcario JK, Manaye KF, SantaCruz KS, Mouton PR, Berman NE, Cheney PD (2004) Severe subcortical degeneration in macaques infected with neurovirulent simian immunodeficiency virus. J Neurovirol 10:387-399.

Marcus CD, Taylor-Robinson SD, Sargentoni J, Ainsworth JG, Frize G, Easterbrook PJ, Shaunak S, Bryant DJ (1998) ${ }^{1} \mathrm{H}$ MR spectroscopy of the brain in HIV-1-seropositive subjects: evidence for diffuse metabolic abnormalities. Metab Brain Dis 13:123-136.

Markowska AL, Stone WS, Ingram DK, Reynolds J, Gold PE, Conti LH, Pontecorvo MJ, Wenk GL, Olton DS (1989) Individual differences in aging: behavioral and neurobiological correlates. Neurobiol Aging 10:31-43.

Masliah E, Ge N, Achim CL, DeTeresa R, Wiley CA (1996) Patterns of neurodegeneration in HIV encephalitis. J NeuroAIDS 1:161-173.

McArthur JC, Steiner J, Sacktor N, Nath A (2010) Human immunodeficiency virus-associated neurocognitive disorders: mind the gap. Ann Neurol 67:699-714.

McCarthy M, Vidaurre I, Geffin R (2006) Maturing neurons are selectively sensitive to human immunodeficiency virus type 1 exposure in differentiating human neuroepithelial progenitor cell cultures. J Neurovirol 12:333-348.

McKinstry RC, Mathur A, Miller JH, Ozcan A, Snyder AZ, Schefft GL, Almli CR, Shiran SI, Conturo TE, Neil JJ (2002) Radial organization of developing preterm human cerebral cortex revealed by non-invasive water diffusion anisotropy MRI. Cereb Cortex 12:1237-1243.

Meyerhoff DJ, MacKay S, Bachman L, Poole N, Dillon WP, Weiner MW, Fein G (1993) Reduced brain $N$-acetylaspartate suggests neuronal loss in cognitively impaired human immunodeficiency virus-seropositive individuals: in vivo ${ }^{1} \mathrm{H}$ magnetic resonance spectroscopic imaging. Neurology 43:509-515.

Meyerhoff DJ, MacKay S, Poole N, Dillon WP, Weiner MW, Fein G (1994) $\mathrm{N}$-Acetylaspartate reductions measured by ${ }^{1} \mathrm{H}$ MRSI in cognitively impaired HIV-seropositive individuals. Magn Reson Imaging 12:653-659.

Moffett JR, Ross B, Arun P, Madhavarao CN, Namboodiri AM (2007) $\mathrm{N}$-Acetylaspartate in the CNS: from neurodiagnostics to neurobiology. Prog Neurobiol 81:89-131.

Mohamed MA, Barker PB, Skolasky RL, Selnes OA, Moxley RT, Pomper MG, Sacktor NC (2010) Brain metabolism and cognitive impairment in HIV infection: a 3-T magnetic resonance spectroscopy study. Magn Reson Imaging 28:1251-1257.

Mukherjee P, McKinstry RC (2006) Diffusion tensor imaging and tractography of human brain development. Neuroimaging Clin N Am 16:19-43, vii.

Mukherjee P, Miller JH, Shimony JS, Philip JV, Nehra D, Snyder AZ, Conturo TE, Neil JJ, McKinstry RC (2002) Diffusion-tensor MR imaging of gray and white matter development during normal human brain maturation. AJNR Am J Neuroradiol 23:1445-1456. 
Müller-Oehring EM, Schulte T, Rosenbloom MJ, Pfefferbaum A, Sullivan EV (2010) Callosal degradation in HIV-1 infection predicts hierarchical perception: a DTI study. Neuropsychologia 48:1133-1143.

Narayan O, Joag SV, Stephens EB (1995) Selected models of HIV-induced neurological disease. Curr Top Microbiol Immunol 202:151-166.

Neeman M, Jarrett KA, Sillerud LO, Freyer JP (1991a) Self-diffusion of water in multicellular spheroids measured by magnetic resonance microimaging. Cancer Res 51:4072-4079.

Neeman M, Freyer JP, Sillerud LO (1991b) A simple method for obtaining cross-term-free images for diffusion anisotropy studies in NMR microimaging. Magn Reson Med 21:138-143.

Neil JJ, Inder TE (2006) Detection of wallerian degeneration in a newborn by diffusion magnetic resonance imaging (MRI). J Child Neurol 21:115-118.

Newton HB (1995) Common neurologic complications of HIV-1 infection and AIDS. Am Fam Physician 51:387-398.

Persidsky Y, Limoges J, McComb R, Bock P, Baldwin T, Tyor W, Patil A, Nottet HS, Epstein L, Gelbard H, Flanagan E, Reinhard J, Pirruccello SJ, Gendelman HE (1996) Human immunodeficiency virus encephalitis in SCID mice. Am J Pathol 149:1027-1053.

Pomara N, Crandall DT, Choi SJ, Johnson G, Lim KO (2001) White matter abnormalities in HIV-1 infection: a diffusion tensor imaging study. Psychiatry Res 106:15-24.

Potash MJ, Chao W, Bentsman G, Paris N, Saini M, Nitkiewicz J, Belem P, Sharer L, Brooks AI, Volsky DJ (2005) A mouse model for study of systemic HIV-1 infection, antiviral immune responses, and neuroinvasiveness. Proc Natl Acad Sci U S A 102:3760-3765.

Price RW, Brew B, Sidtis J, Rosenblum M, Scheck AC, Cleary P (1988) The brain in AIDS: central nervous system HIV-1 infection and AIDS dementia complex. Science 239:586-592.

Ratai EM, Pilkenton SJ, Greco JB, Lentz MR, Bombardier JP, Turk KW, He J, Joo CG, Lee V, Westmoreland S, Halpern E, Lackner AA, González RG (2009) In vivo proton magnetic resonance spectroscopy reveals region specific metabolic responses to SIV infection in the macaque brain. BMC Neurosci 10:63.

Ratiney H, Coenradie Y, Cavassila S, van Ormondt D, Graveron-Demilly D (2004) Time-domain quantitation of ${ }^{1} \mathrm{H}$ short echo-time signals: background accommodation. MAGMA 16:284-296.

Ratiney H, Sdika M, Coenradie Y, Cavassila S, van Ormondt D, GraveronDemilly D (2005) Time-domain semi-parametric estimation based on a metabolite basis set. NMR Biomed 18:1-13.

Reid W, Sadowska M, Denaro F, Rao S, Foulke J Jr, Hayes N, Jones O, Doodnauth D, Davis H, Sill A, O’Driscoll P, Huso D, Fouts T, Lewis G, Hill M, Kamin-Lewis R, Wei C, Ray P, Gallo RC, Reitz M, et al. (2001) An HIV-1 transgenic rat that develops HIV-related pathology and immunologic dysfunction. Proc Natl Acad Sci U S A 98:9271-9276.

Rose SE, Janke AL, Chalk JB (2008) Gray and white matter changes in Alzheimer's disease: a diffusion tensor imaging study. J Magn Reson Imaging $27: 20-26$.

Santoro TJ, Bryant JL, Pellicoro J, Klotman ME, Kopp JB, Bruggeman LA, Franks RR, Notkins AL, Klotman PE (1994) Growth failure and AIDSlike cachexia syndrome in HIV-1 transgenic mice. Virology 201:147-151.

Sas AR, Bimonte-Nelson HA, Tyor WR (2007) Cognitive dysfunction in HIV encephalitic SCID mice correlates with levels of interferon-alpha in the brain. AIDS 21:2151-2159.

Scheller C, Sopper S, Jenuwein M, Neuen-Jacob E, Tatschner T, Grünblatt E, ter Meulen V, Riederer P, Koutsilieri E (2005) Early impairment in dopaminergic neurotransmission in brains of SIV-infected rhesus monkeys due to microglia activation. J Neurochem 95:377-387.

Schifitto G, Zhong J, Gill D, Peterson DR, Gaugh MD, Zhu T, Tivarus M,
Cruttenden K, Maggirwar SB, Gendelman HE, Dewhurst S, Gelbard HA (2009) Lithium therapy for human immunodeficiency virus type 1-associated neurocognitive impairment. J Neurovirol 15:176-186.

Sexton CE, Kalu UG, Filippini N, Mackay CE, Ebmeier KP (2010) A metaanalysis of diffusion tensor imaging in mild cognitive impairment and Alzheimer's disease. Neurobiol Aging. Advance online publication. Retrieved January 17, 2011. doi:10.1016/j.neurobiolaging.2010.05.019.

Simone IL, Federico F, Tortorella C, Andreula CF, Zimatore GB, Giannini P, Angarano G, Lucivero V, Picciola P, Carrara D, Bellacosa A, Livrea P (1998) Localised ${ }^{1} \mathrm{H}-\mathrm{MR}$ spectroscopy for metabolic characterisation of diffuse and focal brain lesions in patients infected with HIV. J Neurol Neurosurg Psychiatry 64:516-523.

Soares DP, Law M (2009) Magnetic resonance spectroscopy of the brain: review of metabolites and clinical applications. Clin Radiol 64:12-21.

Suwanwelaa N, Phanuphak P, Phanthumchinda K, Suwanwela NC, Tantivatana J, Ruxrungtham K, Suttipan J, Wangsuphachart S, Hanvanich M (2000) Magnetic resonance spectroscopy of the brain in neurologically asymptomatic HIV-infected patients. Magn Reson Imaging 18:859-865.

Takahashi M, Ono J, Harada K, Maeda M, Hackney DB (2000) Diffusional anisotropy in cranial nerves with maturation: quantitative evaluation with diffusion MR imaging in rats. Radiology 216:881-885.

Tarasów E, Wiercinska-Drapalo A, Kubas B, Dzienis W, OrzechowskaBobkiewicz A, Prokopowicz D, Walecki J (2003) Cerebral MR spectroscopy in neurologically asymptomatic HIV-infected patients. Acta Radiol 44:206-212.

Thompson KA, Varrone JJ, Jankovic-Karasoulos T, Wesselingh SL, McLean CA (2009) Cell-specific temporal infection of the brain in a simian immunodeficiency virus model of human immunodeficiency virus encephalitis. J Neurovirol 15:300-311.

Toggas SM, Masliah E, Rockenstein EM, Rall GF, Abraham CR, Mucke L (1994) Central nervous system damage produced by expression of the HIV-1 coat protein gp120 in transgenic mice. Nature 367:188-193.

Van Duyne R, Pedati C, Guendel I, Carpio L, Kehn-Hall K, Saifuddin M, Kashanchi F (2009) The utilization of humanized mouse models for the study of human retroviral infections. Retrovirology 6:76.

Wallace MR, Nelson JA, McCutchan JA, Wolfson T, Grant I (2001) Symptomatic HIV seroconverting illness is associated with more rapid neurological impairment. Sex Transm Infect 77:199-201.

Wiley CA (1995) Quantitative neuropathologic assessment of HIV-1 encephalitis. Curr Top Microbiol Immunol 202:55-61.

Williams K, Alvarez X, Lackner AA (2001) Central nervous system perivascular cells are immunoregulatory cells that connect the CNS with the peripheral immune system. Glia 36:156-164.

Williams K, Westmoreland S, Greco J, Ratai E, Lentz M, Kim WK, Fuller RA, Kim JP, Autissier P, Sehgal PK, Schinazi RF, Bischofberger N, Piatak M, Lifson JD, Masliah E, González RG (2005) Magnetic resonance spectroscopy reveals that activated monocytes contribute to neuronal injury in SIV neuroAIDS. J Clin Invest 115:2534-2545.

Yassa MA, Muftuler LT, Stark CE (2010) Ultrahigh-resolution microstructural diffusion tensor imaging reveals perforant path degradation in aged humans in vivo. Proc Natl Acad Sci U S A 107:12687-12691.

Zheng J, Thylin MR, Cotter RL, Lopez AL, Ghorpade A, Persidsky Y, Xiong H, Leisman GB, Che MH, Gendelman HE (2001) HIV-1 infected and immune competent mononuclear phagocytes induce quantitative alterations in neuronal dendritic arbor: relevance for HIV-1-associated dementia. Neurotox Res 3:443-459.

Zink WE, Anderson E, Boyle J, Hock L, Rodriguez-Sierra J, Xiong H, Gendelman HE, Persidsky Y (2002) Impaired spatial cognition and synaptic potentiation in a murine model of human immunodeficiency virus type 1 encephalitis. J Neurosci 22:2096-2105. 